\title{
Social Networking Sites Applications: Theory and Practice
}

\section{Dr. Hasnaa Sabry Abdel-Hamid Helwa}

Lecturer at Department of Curriculum and TEFL

Instruction-Faculty of Education- Benha University- Egypt

Dr.Shaimaa Sabry Abdel-Hamid Helwa

Lecturer at Department of Mass Communication-

Faculty of Specific Education- Benha University- Egypt

\section{Abstract:}

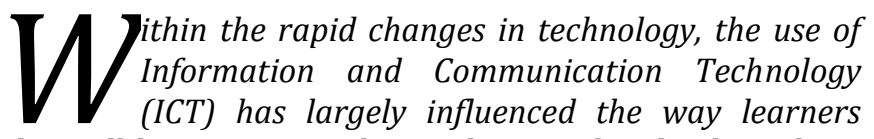

learn. The well-known ICT such social networks also have been widely used by learners to shape their learning. This paper will focus on web-based social learning applications by providing their theoretical background and how they used in practice through studies dealt with them. It can be concluded that through the implementation of web based social learning applications, students' chances for learning by doing and experiences, their belief for better learning and development of learning skills with fun and enjoyment increased. Facebook, Twitter and Edmodo allow students to discuss with peers, give feedback and comment on the writing activities either synchronously or asynchronously.

\section{Introduction}

Within the rapid changes in technology, the use of Information and Communication Technology (ICT) has largely influenced the way learners learn. The well-known ICT such social networks also have been widely used by learners to shape their learning. Therefore, the popularity of social networking websites has created new opportunities for language learners to interact in authentic ways .Through the advances in technology, language learners can easily interact with their peers in meaningful practice that fosters language acquisition and motivation. Thus, the tasks that make use of Web 2.0 interactivity can significantly raise students' attention to generate meaningful output and stimulate their interest in language learning. 
The use of Web 2.0 technologies in education helps students to develop 21stcentury skills. Blogging, wikis and social networks are excellent tools for allowing learners to clarify concepts, establish meaningful links and relationships. Thus, Web-based learning environment can promote constructivist learning through authentic activities related to the vast amount of information available on the Internet. Instructors can provide students with access to variety of tasks available in a combination of formats, such as text, graphics, audio, and video (Mason and Rennie, 2008).

Consequently, Web 2.0 technologies have been widely used as a supplementary learning tool giving students independence in learning. These technologies allow students to express their interests and work collaboratively with teachers, peers, and authentic audience. Also, Shih (2013) clarified that Web 2.0 technologies (e.g. YouTube, Flickr, blog, and Facebook) enable knowledge exchange in ways such as online meeting and discussion .Through these applications, users are able to exchange, interact, collaborate, and socialize with others in virtual communities.

Therefore, it is known that social networks such as Facebook, Edmodo, Twitter, Ning, MySpace, weblogs and wiki used mostly by teenagers and adults, are seen to be used not for doing research and getting information but for talking with friends, introducing oneself to others and mostly playing games. The concept of societal network which emerges from Web 2.0 means individuals tied one another with one or more social connections and therefore individuals constructing societal connections (Donmus, 2010).

This paper will focus on web-based social learning applications by providing their theoretical background and how they used in practice through studies dealt with them.

\section{The Theoretical Background}

Social media are a collection of Internet websites, services, and practices that support collaboration, participation, and 
sharing. These technologies have attracted the interest of higher education faculty members looking for ways to engage and motivate their students to be more active learners. Thus, there has been interest in integrating various social media tools (such as blogs, microblogs, video-sharing sites, and social networking) into the learning process. A major category of social media activity is social networking. Social networking websites (SNSs), such as Facebook, Myspace, and Twitter, have become integral to learning .While Facebook has been the most popular social networking site for college students to date, educators have been more willing to try to integrate Twitter as part of the learning process. Twitter is a blog that is restricted to 140 characters per post but that also includes the functionality of social networking (Junco, Heibergert and Loken, 2011).

Social networking tools provide a good environment to support educational activities by providing interaction, collaboration, active participation, sharing information and critical thinking. SNSs such as Facebook, Twitter and Edmodo allow access to more resources in terms of learning and sharing. Through social networking tools, individuals can establish their social networks, share latest news, videos, educational subjects, interesting stories as well as having the opportunity to be followed by other users. As a result, teachers should use various Web 2.00 tools on SNSs to develop new teaching tools, that help students to improve and practice their language skills (Bicena, Sadıkoglubb and Sadıkoglub, 2015, Mali and Hassan, 2013).

Therefore, SNSs can be defined as an online computer network through which people interact and bond with each other. It is a virtual society where one can know other people and communicate with them. Social Media create a new community where teachers and students do not have to communicate by means of the traditional face-to-face classroom environment. Thus, SNSs have come to play an important role in developing a person's communication skills. These sites give ample scope to the users to create and edit their profiles, video chatting, write blogs, etc (Kalasi,2014). 
Thus, Silius, et.al. (2010) indicate that Web 2.0 based social media services (e.g. Facebook, LinkedIn, Last.fm) have recently become well known especially among young people. In SNSs a user can participate intensively in activities in the service, share contents, debate and share opinions and create different kinds of groups for different needs. Arnold and Paulus (2010) clarifies that web based social learning are also confirmed to be effective teaching tools because most students already have accounts and their platforms are ready-to-use. SNSs provide additional features that are media sharing, tagging, own brand and visual design, real time activity stream, groups, friends, and profile pages. They are not extensively adopted in the education field as much as in other fields. Some social networks tools were applied in teaching and learning such as Twitter, Facebook, Edmodo and Ning.

Purcell (2012) clarify that students frequently using SNSs are often successful in their learning and they suggest that teachers should create learning opportunities for students to interact with one another on various SNSs. Boyd and Ellison (2007) defined SNSs as web-based services that allow individuals to construct a public or semi-public profile within a bounded system, articulate a list of other users with whom they share a connection, and view their list of connections and those made by others within the system. El-Sawy (2015) clarifies that SNSs go along with social constructivism theory of learning and the zone of proximal development which emphasizes that learners can learn in association with others much more than what they can learn alone.

Therefore, with web applications on the internet like SNSs , it would be an easy task to encourage students to use them as a medium to learn and improve their language skills. Students' perceptions on learning writing using the internet should be fully recognized, as it would serve its purpose to revitalize the learning process in class. The internet comprises of web applications that have helped to maintain relationships and individual interests. Applications such as Facebook, Edmodo, 
Twitter, YouTube, Ning, MySpace and others serve a purpose of communicating with one another, even across distances. These are known as SNSs.

Web based social learning includes variety of application such as Edmodo, Facebook and Twitter. Thus, this paper will focus on these three applications.

Edmodo was created by Nic Borg and JeffO'Hara (2008) who realized the need to evolve the school environment to meet the connectedness of the $21^{\text {st }}$ century world. It is a safe environment that might enhance students' learning. Teachers post announcements and assignments for their students. Students use Edmodo to communicate with their teachers to ask questions about lessons and homework and collaborate with other classmates on activities and project ideas. Using Edmodo, students and teachers can reach out one another and connect by sharing ideas, problems and helpful tips. A teacher can assign and grade work on Edmodo and students can get help from the entire class on Edmodo (Mills and Chandra, 2011).

Qalaja (2015) indicates that Edmodo is a social networking website used for educational purposes. The Edmodo application is much like the commonly used Facebook website. Like Facebook, Edmodo is a site designed to keep people in touch with those who have similar interests and goals. It creates an online environment for teachers and students to stay connected in an educational setting. This online learning space creates a secure environment for a class to share ideas, files, and assignments through mobile access and messaging. Edmodo is an educational network that has the social and sharing elements of Web 2.0. It lets teachers and students collaborate online, share content, access homework assignments and join online discussions in a safe environment.

Edmodo is a web-based social learning platform for teacher and students. It provides teachers and students with a closed, private online community to encourage communication and 
collaboration. It can be incorporated into the classroom through a variety of applications including reading, assignments, and paper-studying. Current uses include posting assignment, creating polls for student response, embedding video clips, creating learning groups, posting quizzes for students to take, and creating a calendar of events and assignments (Redman ,2012).

Therefore, Redman and Trapani (2012) also reported on how Edmodo, an SNS with strong ties to education, effectively provided a space for communication, virtual collaboration, and organization of pertinent digital resources. Also, Qalaja (2015) indicated that Edmodo has several characteristics such as it offers different levels of interaction; students get to work on educational assignments while using a fun platform; teachers can easily differentiate assignments for students on different achievement levels and students can work individually or cooperatively.

Also , Alfian (2013) clarified that Edmodo is used by students to get collaborative writing activity in which they are doing a writing process like planning, drafting, editing, and publishing. In the planning process, students are engaged in selecting the topic they were going to write. In the drafting process students are asked to write a draft by using a brainstorming in order to help them write in a good sequence. Meanwhile, in the editing process students are asked to work in a group and share their writing draft to be checked by the group members. Finally in the publishing process, students are asked to post their writing on Edmodo. While students are posting their writing on Edmodo, the writer asks another group to check and give the comment on that writing so that students are able to give comment and correction to each other as a revision to their writing.

In addition to Edmodo, SNSs like Facebook have become commonplace in the lives of young adults around the world. Facebook is defined as a social utility that helps people share information and communicate more efficiently with their 
friends. Originally it started as a medium for college student interaction. It enables peer feedback and can be a good vehicle to enhance communication in and outside the classroom environment (Mali and Hassan,2013, Mason,2006, Rose,2014, Tartari,2014).

Mazer, et al. (2007) clarifies that Facebook as a virtual SNSs facilitates computer-mediated communication (CMC), can facilitate interaction between the teacher and his/her students and increase learners' motivation and ability to learn. Wichadee (2013) indicates that among many technologies, Facebook is the most popular social networking website for college students. They usually use Facebook to discuss and share photos among friends.

Reid (2011) confirms that Facebook is a literacy practice within the domain of social networking, which is governed by certain values, such as establishing and negotiating identity, building relationships, staying connected, conciseness and immediacy. Arnold and Paulus (2010) indicate that Facebook has many features such as the "like" button, comment application and sharing button. These features have attracted users to create discussion and share their thoughts instantly. It gives people the power to share and make the world more open and connected, creates space for autonomy and engagement in exchanging ideas and knowledge due to active roles consumed by learners.

As a result, Wichadee (2013) indicates that one possible way of using Facebook for writing development is to make a group to exchange feedback. When compared with face-to-face environment, peer feedback on Facebook provides more opportunities for students to practice communication with their peers. The peer feedback activity on Facebook that blends written and electronic communication can promote student motivation, participation, and collaboration among peers. Thus, Facebook is an interesting learning tool for teaching and learning due to its positive outcomes. It is a valuable tool for students to learn and work together, and the results revealed students' 
achieving better grades, higher engagement, and greater satisfaction with the university learning experience.

Twitter is described as a social networking and microblogging service that users like to use for short messages of 140 characters in length. The short format is a unique way of communicating that has captivated the creative minds of millions of users and it is an interesting method for students to keep in touch with each other as well as with the teacher. One possible lesson may start with a teacher telling a story to the learners. Then, the teacher instructs the students to continue the story. Another idea may be for the teacher to ask trivia questions, and the students attempt to answer them in class (Chartrand, 2012).

Mork (2009) clarifies that Twitter forces users to be as concise as possible, which is part of the appeal of the system. The rest of the attraction lies in its real-time content that encourages people to befriend each other and interact with each other to a much higher degree than previous SNS models .Twitter users keep track of other users by clicking the "follow" button on the latter's profile page. When individual users are followed, their updates are put together in a "feed" that their followers can easily peruse. These feeds are updated in real time, right in front of the user. Because the posts are so short, people can easily blog about things as they are happening. Therefore, Deyamport (2013) defined Twitter as a microblogging (short postings on a blog or social network), social networking site that allows teachers to connect, collaborate, share, and participate in chats.

Twitter is a social networking application that allows people to microblog about a broad range of topics. Users of Twitter post short text, called "tweets", on a variety of topics as news events and pop culture, to mundane daily events and spam. Recently, Twitter has grown over 200 million active users producing over 200 million tweets per day. It is a popular social communication tool for short and clear expressions which can be produced simply and viewed by everyone with access to the internet (Yavuz, 2014). 
Cheng (2012) indicates that Twitter's advantages for enhancing social interaction and learning experiences can be described as experiential learning. Experiential learning engages learners in activities in which they have the ownership of learning autonomy and can experience and develop social presence and problem solving abilities. Incorporating Twitter into a class creates a new way of communication that stimulates the learner's cognitive process in perceiving and handling new tasks or information. It contains a constructive and positive learning community that guides students' learning objectives by encouraging them to tweet intellectually or emotionally. Twitter provides users with the ability to view and comment upon others' tweets. The instructor plays the role of facilitator by observing and offering constructive feedback.

In addition, Mork (2009) indicates that Twitter has main advantages for teachers. Teachers can use the platform to send reminders to students about assignments, tests, etc. Twitter sends a text message when a person they follow updates. Teachers can post links to news stories, relevant websites, or even the Twitter profiles of important people. Assignments on Twitter give students the opportunity to work on this writing skill. Twitter may actually be good for teaching grammar. Many who tweet often abbreviate and abuse grammar rules, developing a unique sort of Twitter shorthand, making messages really difficult for the uninitiated to understand in the process. Hattem(2014) indicates that on Twitter, users interact with tweets through a variety of features by replying to messages using the @ symbol as a form of addressivity, by favoring a tweet (similar to the Like function on Facebook) or by retweeting it so that all of followers can also see it. In order to aggregate the abundance of messages into topics, users attach hashtags to their tweets, which are words denoting topics, preceded by the \# symbol.

Therefore, in Twitter, the method of engaging in social interaction, discussion, and collaborative learning is based on an asynchronous form of written communication. Tweets allow 
instructors to track each learner's writing progress and ideas. Posting comments offers students a chance to practice using the language for situational communication while also giving teachers a chance to observe the actual performance of students' comprehension in their target language. Twitter can facilitate collaborative writing in class and can serve as a platform for idea stimulation among multiple users. Twitterers (i.e., people who use Twitter as a way of engaging social interaction) are able to construct their sentences in the form of tweets and communicate with other individuals and social groups (Cheng, 2012).

Tweeting is differing from other forms of communication in that students can only type 140 characters in a tweet including spaces. While texting can be similar to a tweet, a text is only sent to a specific person or group of people and is not posted on the internet. SNSs such as Facebook differ from Twitter in that Facebook does not limit the characters used. While all forms of social media can be helpful to find information quickly, keep in mind that many are biased because a person wants to specifically share his or her opinion exclusively (Kahler, 2014, Lightle, 2010 cited in Deyamport, 2013, Richardson, 2006).

In conclusion, it can be said that, using web based social learning applications has an essential role in enhancing language skills, learner motivation, improving learning performance and prompting positive changes in their roles in learning.

\section{The practical Part: Studies dealt with Web Based Social Learning Applications:}

Internet can be used in a variety of ways to support process writing as students develop their writing skills in various genres. In addition, teachers who have never used blogs or social media for the development of process writing might feel lost about what steps to take to make the activities interactive and motivating. The instructors can consult widely available and user-friendly online resources to make the technology accessible. For example, Edmodo, Facebook and Twitter networks are three 
widely used online platforms that can be easily researched and adapted to all stages of the process approach (Boas,2011).

Piriyasilpa (2011) clarified the effects of providing students with opportunities for social networking as a means of using language learnt in the classroom. The participants were 134 first-year students at a university in Thailand. The topics were advised by the teacher and students were asked to make comments or discuss their opinions on the teacher's wall. She found out that such incorporation was useful for students to create their social network and it was also beneficial for supporting language learning.

Dixon (2012) clarified the process of using SNS in teaching English by gathering information on student engagement with Facebook, and describing non-native English speakers' (NNS) expectations and experience when using SNS in learning. He also assessed the relationship this technology has with writing efficacy and compared NNS and native English speakers (NS) groups. Results revealed that the majority of students are on Facebook, and that they tend to spend approximately 30 minutes per day on the site, checking in almost every day.

Leonard (2012) conducted a study to understand how students perceive a combination of three strategies, social networking, the writing process, and cooperative learning may help students to be successful with the prewriting phase of the writing process. Nine students across four sections of writing courses agreed to participate in this qualitative inquiry. Data were collected from semi-structured interviews, social networking posts, observations, and a researcher-made handout. Results revealed that students perceived a social networking tool to be beneficial to help them learn, and achieve their ideas. It influences prewriting in cooperative groups by generating ideas, representing their contributions, and communications with group members. Finally, the participants' perceptions and observations revealed that working together in cooperative groups to prewrite reflected the five elements of cooperation 
Bicena, Sadıkoglubb and Sadıkoglub (2015) determined how much undergraduate students benefit from SNSs while learning $a$ foreign language. The participants were 85 undergraduate students. Results revealed that students have stated that there is a positive effect of SNSs on learning foreign languages. Students mentioned that they follow professional foreign language teachers and various facilities used for speaking in order to improve their speaking skills. It was also stated that students prefer to use automatic translations in order to decrease the problem of understanding the news that they read on social networking sites.

El-Sawy (2015) investigated students' perceptions of integrating SNSs in language learning. A project integrating SNS (Facebook as an example) was designed to give students an opportunity to use a Facebook group in their language learning process. Fifty seven third year basic education, English department students participated in the project during a complete academic year at Damanhour university, Egypt. A questionnaire was prepared and used to enquire students' perceptions. Results of the study indicated that the majority of participants perceive SNS as beneficial in language learning. The most perceived benefits include improvement in a lot of aspects including self-confidence in writing, all language skills especially writing, increased vocabulary, grammar, motivation, interaction among students and between students and teachers, creative skills, exposure to language, cooperation and thinking in English. Participants also declared that they prefer writing and reading short posts than long ones.

Through using Edmodo, teachers build community, organize communication, collect student work, and disseminate grades. Using technology like Edmodo in writing classes provides opportunities for students to hand their written work to the teacher without the need for any face-to-face interaction. It can increase their self-efficiency and success and help decrease their anxiety in the process of writing. It is a means of enlivening instruction, improving students' writing skills, and facilitating 
collaboration and interaction both within and beyond the classroom (Shams-Abadi, Ahmadi and Mehrdad ,2015).

Alfian (2013) investigated the utilization of a microblogging, Edmodo in particular, to be used as a tool in teaching writing to the tenth grade students of Al-Azhar. As the instrument, the researcher used triangulation technique. He did the observation, gave the questionnaire to the students, and did an interview with several students. The results revealed that the utilization of Edmodo micro-blogging in which the process approach used in its activity such as writing for an audience, peer review, self-editing and revising impacted the students writing quality.

Fauzi (2015) examined the use of Edmodo to increase the first graders' skill in composing recount text. The study used quantitative approach with pre-experimental design. The participants were 9 students from excellent program. Before starting the treatment, two similar tests were prepared as the pretest/posttest to find out students' writing skill in recount text at the beginning and at the end of the study. The finding showed significant differences between the result of pretest and posttest in favor of the posttest.

McClain, Brown and Price (2015) evaluated how an education-based social networking site affected student engagement with literature in a secondary English classroom. Twenty-two students from an $11^{\text {th }}$ grade English class used Edmodo as a tool for role-playing literary characters. Findings revealed that students engaged in meaningful interactions with classmates as well as their respective characters during roleplaying activities. In addition, digital tools such as Edmodo can provide a truly collaborative work space for students beyond the classroom walls, promote various avenues for constructive learning, and encourage higher order thinking skills.

Qalaja (2015) investigated the effectiveness of using Edmodo as a teaching and learning virtual class to the product writing approach on enhancing Palestinian $7^{\text {th }}$ 
graders English writing skills and their attitudes towards writing .The participants were 50 EFL female students studying at Al Majda Wasella prep "B" Girls' School in Gaza. The tools of the study consisted of a writing skills test and writing attitudes scale. Results revealed that there were statistically significant differences between the mean scores attained by the experimental group and that attained by the control group in the post writing skills test and writing attitudes scale in favor of the experimental group. This showed a remarkable improvement in English writing performance and attitudes of the experimental group students.

Shams-Abadi, Ahmadi and Mehrdad (2015) investigated the effect of Edmodo on EFL learners' writing performance. A quasi-experimental design was used in their study. The participants were 40 female advanced-level students attending advanced writing classes at Iranan English Institute. The students were randomly assigned to two groups, experimental and control. Edmodo was used in the experimental group. Results indicated that the use of Edmodo in writing was more effective in EFL learners' writing performance participating in the study.

Facebook is a website that allows users to interact and collaborate within a pre-defined virtual community. Irwin , Ball ,Desbrow and Leveritt (2012) defined it as an online communication tool allowing users to construct a public or private profile in order to connect and interact with people who are part of their extended social network. Also, Eren (2012) indicated that on Facebook, people from all ages can create their own profiles, write each other's walls and share their favorite photos and videos. It also has applications useful for teaching and learning. It is a technological tool which can nurture the student-teacher relationship by creating positive learning experiences for both parties.

Alias, Ab Manan, Yusof, and Pandian, (2012) investigated the effects of Language Learning Strategy (LLS) training using 
Facebook notes on the students' strategies use during the four stages of their writing process and academic writing performance. Forty students participated in the study. The design of the study was quasi-experimental with non-equivalent experimental and control group pre-tests and post-tests. Results revealed that the use of Facebook Notes as LLS training tool promotes the use of indirect LLS among college students in the study. Results showed that the experimental group learners use the strategies more frequently.

Eren (2012) investigated students' attitudes towards the use of SNS, Facebook in particular, in language classroom. The participants of the study were 48 undergraduate students at a university in Gaziantep, Turkey. The instruments of the study included questionnaire and semi-structured interviews. Results revealed that students have a very positive attitude towards the use of Facebook activity as a supplement to language classroom, but traditional classroom based language learning still remains a backbone for language education.

Suthiwartnarueput and Wasanasomsithi (2012) explored the effects of using Facebook as a medium for grammar and writing discussions of low-intermediate EFL students. The data were collected from the students' utterances asking for explanations about English grammar and writing that were posted on Facebook, their gain scores in the pre-test and posttest, and interview responses. The findings showed a statistically significant difference between the mean scores of the pre-test and the post-test. It was found that English grammar was worth promoting for discussions on Facebook because there were correlations between the gain scores in the grammar and writing parts. The students also had positive attitudes toward using Facebook as a means of learning grammar and writing.

Yunus and Salehi (2012) investigated students' perceptions on the effectiveness of Facebook groups for teaching and improving writing. The participants were 43 third year students, at the Faculty of Education, University Kebangsaan, Malaysia. The students' perceptions were measured through a questionnaire 
comprising 10 close-ended items and 3 open-ended ones. Students were required to participate in a Facebook group created by the researchers. Results showed that "Facebook group" is an effective tool in improving the students' writing skills, especially in the brainstorming of ideas before the actual writing.

Abdallah (2013) implemented a Community of Practice (COP) design facilitated by Facebook to integrate some new forms of online writing. Participants consisted of seventy 3rdyear EFL student teachers at Assiut University College of Education. Tasks were administered both face to face and online (mainly through Facebook). In response to them, participants contributed with posts and comments, which were qualitatively analyzed to inform the process of evaluating the intervention by establishing some conclusions in the form of design principles and lessons learned to be cycled back into future attempts within the same context.

Mali and Hassan (2013) investigate the level of acceptance of using Facebook as a learning tool among students in a Public University in Kuala Lumpur.The design of this study was a triangulation of quantitative and qualitative methods. A self-constructed questionnaire with (25) items was used to measure the perceived ease of use, perceived usefulness and students' attitude toward using Facebook as a learning tool. The survey was carried out to a purposive sampling where only students who used Facebook in learning were selected. Three students were selected for the interviews. Results indicated that there was no significant difference between male and female in their intention to use Facebook as a learning tool..

Shih (2013) explored the effect of incorporating blended learning with Facebook and peer assessment for English for Business Communication course among college students. The participants were 111 students from a public technological university. They were divided into three Facebook site groups. A mixed method consisting of qualitative and quantitative 
approaches was employed to analyze the collected data, including the pre- and post-tests, qualitative data of peer assessment on Facebook sites, interview, a student self-efficacy scale, and a self-developed satisfaction survey questionnaire. Results indicated that incorporating Facebook in the English for Specific Purposes (ESP) course can effectively assist college students in learning business communication English.

Wichadee (2013)explored Facebook with peer feedback in groups supports student learning, investigated the nature of feedback students received on their writing, and examined their attitudes towards the use of Facebook for peer feedback. The participants were 30 undergraduate students .. Data were collected from the first and final drafts of writing assignments, written peer comments, a questionnaire and an interview. The results revealed that the nature of students' feedback focused on content more than grammatical errors. However, quantitative analyses of the peer comments and revisions to the drafts showed that feedback given on Facebook had an effect on improving revised drafts. There was statistically significant improvement in the revised drafts which was linked to peer feedback. Finally, the analysis of interviews indicated positive attitude on the use of Facebook for peer feedback in the English class.

Bani-Hani1, Al-Sobh and Abu-Melhim (2014) investigated the perceptions and attitudes of Jordanian EFL students' at Irbid University College-Al-Balqa Applied University towards utilizing Facebook groups in teaching writing. They also investigated the role that Facebook groups play in enhancing the writing performance level and brainstorm ideas at the pre-writing stage. A survey consisting of ten questions was used to assess these factors. The participants were $42 \mathrm{EFL}$ students at the department of English Language and Literature. Results revealed that Facebook groups can be effective in teaching EFL writing. Furthermore, results illustrated that students can develop their vocabulary by being exposed to fellow group members' posts, in addition to checking for misspelled words. 
Cheng (2012) explored the potential language learning value of applying Twitter as a tool for reading and writing in a college setting in Taiwan. Participants completed pretests and posttests to assess reading and writing. Both of the groups experienced the same learning materials and teaching methods, but the non-Twitter group engaged in free-writing activities while the Twitter group used Twitter for major course writing exercises. Results revealed that Twitter-assisted learning had a significant positive influence on the experimental group's learning attitude.

Larreta-Azelain (2013) investigated the effects of microblogging on written foreign language learning. Twitter is used to analyze the usefulness of microblogging to improve students' motivation in writing because it enables users to post only short messages limited to 140 characters, so it is more suitable for the initial language level of students. The participants were university students at University of Distance Education. The instrument of the study was a questionnaire to determine student profiles, social networking habits and attitudes towards Web 2.0 tools for learning. Results revealed that Twitter facilitates students' writing processes in a foreign language.

\section{Conclusions:}

It can be concluded that through the implementation of web based social learning applications, students' chances for learning by doing and experiences, their belief for better learning and development of learning skills with fun and enjoyment increased. Moreover, their emphasis on certain personal developments such as thinking, self-confidence, communication skills and team spirit and their consideration of instructor as a guide for learning .Using SNSs such as Facebook is widely used all over the world by people including students. Facebook is currently the fastest growing and the most preferred social networking site in the world. It is thought that adding educational games in such a popular social site can substantially contribute to ease the communication of students and increase students' motivation for learning. Students continuously 
interacting in Facebook will possibly benefited from educational games for their learning. With Facebook, more meaningful learning environment can be created and comment feature makes the learning process more easy and fun. Also, Facebook, Twitter and Edmodo allow students to discuss with peers, give feedback and comment on the writing activities either synchronously or asynchronously.

Therefore, it can be concluded that using technology in language classes provide opportunities for students to hand their written work to the teacher without the need for any faceto-face interaction. Therefore, it can be observed that access to the online tools can provide opportunities to improve the writing ability, as it provides easy access to online sources and enables learners to compare their written essays with other classmates in their group and other groups, to have collaborative activity, and to keep in touch with the teacher and other learners any time they wish. Collaborative learning can increase students' interest in learning, especially when the students are actively exchanging and negotiating ideas, engaging in discussion and taking responsibility for their learning.

\section{References:}

Abdallah, M. M. S. (2013). A Community of Practice Facilitated by Facebook for Integrating New Online EFL Writing Forms into Assiut University College of Education. Journal of New Valley Faculty of Education 12(1), Assiut University ,581-650.

Alfian, A. (2013). Micro-blogging assisted learning strategy in teaching writing (CA Classroom Action Research at the Tenth Year Students of SMA Al-Azhar BSD in 2011/2012 Academic Year).Unpublished master thesis, Faculty of Tarbiya and Teacher Training, State Islamic University Syarif Hidayatullah Jakarta, Indonesia.

Alias, A. ; Ab Manan, N.; Yusof, J. \& Pandian, A. (2012). The Use of Facebook as Language Learning Strategy (LLS) Training Tool on College Students' LLS Use and Academic Writing 
Performance, Procedia - Social and Behavioral Sciences 67, $36-48$.

Arnold, N. \& Paulus, T. (2010). Using a social networking site for experiential learning: Appropriating, lurking, modeling and community building. Internet and Higher Education, 13, 188- 196

Bani-Hani1, N.A., Al-Sobh, M.A. \& Abu-Melhim, A.H. (2014). Utilizing Facebook Groups in Teaching Writing: Jordanian EFL Students' Perceptions and Attitudes. International Journal of English Linguistics, 4(5), 27-34.

Bicena, H., Sadıkoglub, S. \& Sadıkoglub, G. (2015). The Impact of Social Networks on Undergraduate Students Learning Foreign Language. Procedia - Social and Behavioral Sciences 186, 1045 - 1049.

Boas, I.V. (2011). Process Writing and the Internet: Blogs and Ning Networks in the Classroom.English Teaching Forum, (2) ,26-33.

Boyd, D.M. \& Ellison, N.B. (2007). Social Network Sites: Definition, History, and Scholarship. Journal of ComputerMediated Communication 13(1), 210-230.

Chartrand, R. (2012). Social networking for language learners: Creating meaningful output with Web 2.0 tools. Knowledge Management \& E-Learning: An International Journal, 4(1), 97-101.

Cheng, H.Y. (2012). Applying twitter to EFL reading and writing in a Taiwanese college setting. Unpublished doctoral dissertation, Indiana State University, Terre Haute, Indiana.

Cheng, H.Y. (2012). Applying twitter to EFL reading and writing in a Taiwanese college setting. Unpublished doctoral dissertation, Indiana State University, Terre Haute, Indiana. Deyamport, W.H.(2013). An implementation of a twittersupported personal learning network to individualize teacher professional development. Unpublished doctoral dissertation, Capella University

Dixon, G. (2012). Facebook, Writing and Language Learner Variables at a Large Metropolitan Community College, Unpublished doctoral dissertation, Faculty of the University of Kansas. 
Donmus, V. (2010). The use of social networks in educational computer-game based foreign language learning. Procedia Social and Behavioral Sciences 9, 1497-1503.

El-Sawy, S.E.A. (2015).Students' Perceptions of Integrating Social Networking Sites in Language Learning: Benefits and Challenges. Journal of Research in Curriculum, Instruction and Educational Technology (JRCIET),1(2),149-177.

Eren, 0. (2012). Students' Attitudes towards Using Social Networking in Foreign Language Classes: A Facebook example. International Journal of Business and Social Science, 3(20), 288-294.

Fauzi, a(2015). The Effectiveness of Edmodo in Increasing Students' Writing Skilll in Recount Text (An Experimental Study towards The First Graders of MAN Rejotangan in Academic Year 2014-2015). Unpublished Master thesis, Faculty of Tarbiyah and Teacher Training State Islamic Institute of Tulungagung.

Hattem, D. (2014). Microblogging activities: language play and tool transformation. Language Learning \& Technology, 18(2), 151-174.

Irwin, C., Ball, L., Desbrow, B. \& Leveritt, M. (2012). Students' perceptions of using Facebook as an interactive learning resource at university. Australasian Journal of Educational Technology, 28(7), 1221-1232.

Junco, R., Heiberger, G., \& Loken, E. (2011). The effect of Twitter on college student engagement and grades. Journal of Computer Assisted Learning, 27(2), 119-132.

Kahler, J. (2014). Technologically-mediated writing in the first year writing classroom: twitter and immediate writing. Unpublished doctoral dissertation, Wayne State University, Detroit, Michigan.

Kalasi, R. (2014). The Impact of Social Networking on New Age Teaching and Learning: An Overview. Journal of Education \& Social Policy, 1(1) ,23-28.

Larreta-Azelain, M.D.C.D. (2013). Learners attitudes toward collaborative writing in e-language learning classes: a 
twitter project for German as a foreign language. RESLA 26, 127-138.

Leonard, B.(2012).Social networking, the writing process, and cooperative learning: a three-strategy approach helping developmental students and first-year composition students prewrite. Unpublished doctoral dissertation, The University of Memphis.

Lightle, K. (2010) cited in Deyamport, W.H.(2013). An implementation of a twitter-supported personal learning network to individualize teacher professional development. Unpublished doctoral dissertation, Capella University.

Mali, A.S.M. \& Hassan, S.S.S. (2013). Students' acceptance using Facebook as a learning tool: a case study. International Journal of Asian Social Science, 3(9):2019-2025.

Mason, R. \& Rennie, F. (2008). E-Learning and Social Networking Handbook: Resources for Higher Education. New York: Routledge.

Mason, R. (2006). Learning technologies for adult continuing education. Studies in Continuing Education, 28(2), 121133.

Mazer, J. P., Murphy, R. E. \& Simonds, C. J. (2007). I'll see you on "Facebook": The effects of computer-mediated teacher self-disclosure on student motivation, affective learning, and classroom climate. Communication Education 56(1), 1-17.

McClain, C., Brown, A., \& Price, G. (2015). Characterization Personified: Using Edmodo to Strengthen Student Interaction with Literature. Meridian: $A$ K-16 School Computer Technologies Journal, 18,1-19.

Mills, K, \& Chandra, V. (2011). Microblogging as a Literacy Practice for Educational Communities. Journal of Adolescent \& Adult Literacy, 55(1), 35-45.

Mork, C.M.T. (2009). Using Twitter in EFL Education. The jalt calljournal, 5(3) ,41-56.

Piriyasilpa, Y. (2011). See You in Facebook: The Effects of Incorporating Online Social Networking in The Language 
Classroom. Journal of Global Management Research, 7(1) ,67-80.

Purcell, A.M.(2012). The Networked Library: A Guide for the Educational Use of Social Networking Sites. California: Linworth.

Qalaja, M.W.M. (2015). The Effectiveness of Using Edmodo on Developing Seventh Graders' Writing Skills and their Attitude towards Writing in Gaza Governorate. Unpublished master thesis, Faculty of Education, The Islamic University-Gaza.

Redman, C., \& Trapani, F. (2012). Experiencing new technology: Exploring pre-service teachers' perceptions and reflections upon the affordances of social media. (An online Eric database full text No.ED542340).

Reid, J. (2011).We don't Twitter, we Facebook": An alternative pedagogical space that enables critical practices in relation to writing. English Teaching: Practice and Critique, 10(1) ,58-80.

Richardson, W. (2006). Blogs, wikis, podcasts, and other powerful web tools for classrooms. Thousand Oaks, CA: Corwin Press.

Rose, C.A. (2014). ESL Student Perceptions of the Value of Facebook in the IEP Classroom. Unpublished master thesis, University of Minnesota

Shams-Abadi, B.B., Ahmadi, S.D. \& Mehrdad, A.G. (2015). The Effect of Edmodo on EFL Learners' Writing Performance. International Journal of Educational Investigations, 2(2) ,8897.

Shih, R.C. (2013). Effect of using Facebook to assist English for business communication course instruction. TOJET: The Turkish Online Journal of Educational Technology, 12 (1), 52-59.

Silius, K., Miilumäki, T., Huhtamäki, J., Tebest, T., Meriläinen, J. \& Pohjolaine, S. (2010). Students'Motivations for Social Media Enhanced Studying and Learning. Knowledge Management \& E-Learning: An International Journal, 2 (1), 51-67.

Suthiwartnarueput, T. \& Wasanasomsithi, P. (2012). Effects of Using Facebook as a Medium for Discussions of English 
Grammar and Writing of Low-Intermediate EFL Students. Electronic Journal of Foreign Language Teaching, 9(2), 194214.

Tartari, E. (2014). Facebook Use through Mobile Devices by Teenagers in Albania. Journal of Educational and Social Research, 4(4) ,88-91.

Wichadee, S. (2013). Peer feedback on Facebook: The Use of Social Networking Websites to Develop Writing Ability of Undergraduate Students. Turkish Online Journal of Distance Education-TOJDE 14 (4), 260-270.

Yavuz, M. (2014). Evaluation of Twitter Users Writings about Teachers in Turkey. Educational Sciences: Theory \& Practice, 14(4), 1325-1338.

Yunus, M. \& Salehi, H. (2012). The effectiveness of facebook groups on teaching and improving writing: Students' perceptions. International Journal of Education and Information technologies, 6 (1), 87-96. 
